\title{
Green House Smart Farming Echosystem
}

\author{
${ }^{1}$ Stella I. Orakwue and ${ }^{2}$ Douglas S. Otonye \\ ${ }^{1}$ Electrical/Electronic Engineering Department, University of Port Harcourt, Nigeria. \\ ${ }^{2}$ Centre for Information and Telecommunications Engineering, University of Port Harcourt, Nigeria
}

\begin{abstract}
The future of farming has been one of the most talked-about issues on world forums, with the world population increasing yearly there is a special need to develop more efficient ways to grow food and distribute them effectively. This work discusses the design and implementation of a greenhouse smart farming echo system for the cultivation and distribution of plants using mushrooms as a focused product, linking a farm environment to a business market (cultivation processes and supply chain). A green house farm smartly monitored with embedded devices, a control interface for these devices, and a web platform for product distribution and consumer management platform was developed to create a unified smart agricultural echo system. The embedded system has sensors that monitor the levels of light, temperature, soil moisture and humidity and automatically open the tap to water the farm. In addition, the supply chain was designed for the distribution of farm products. The prototype was fabricated and tested. The results showed that both the electronic part and the supply chain are working as proposed.
\end{abstract}

Keywords: Smart farming, Embedded systems, Sensors, Electronic Commerce technology,

\section{Introduction}

Greenhouse smart farming is an emerging concept that refers to the digitalization of agriculture by using modern information and communication technologies to automate agricultural processes (cultivation and supply-chain management). Agricultural processes are getting smarter in this era of digital transformation with more automated processing methods and business intelligence for agronomic information to illuminate, predict and affect the continuum of cultivation issues across farm businesses [1,2]. Agriculturists rely upon their gut to figure out the vital operations which can have an adverse effect on their production. However, the use of data from sensors [3] and customer relationship management interfaces [4] with farmers can be able to optimize production from anywhere in the world. These digital technologies have revolutionized agriculture by helping farmers work more precisely, efficiently and sustainably. Data-driven insights can improve decision-making and help increase environmental and economic performance.

With new technologies now in use to achieve smart farming, improved planning and production is now achievable (precision farming) [5,6]. The global agro-food supply chain still remains an inherently complex system, it is a globalized system made up of many moving and dysfunctional parts that makes it more complicated to manage. It is estimated that by 2050 the world population could hit +9billion [7] (this means that the food consumption will rise and the supply chain will become much more tasking). Keeping track of where food is grown has been difficult and this leads to food insecurity.

Managing farm businesses usually requires farm owners to use multiple platforms/software to carry out varying tasks on and of the farm, this leads to poor data management and optimization.

With the world fast-evolving, optimizing digital strategies for food/agricultural product management is one of the most talked-about topics on world forums, amidst concerns of climate change and its effects on our environment, and this work integrates precision farming and supply chain.

\section{Design Method And Implementation}


The development of the greenhouse smart farming echo system was done by carrying out a review of related previous works to exploit knowledge gaps, adopting an approach to design and implement the system by gathering functional specifications/requirements for all levels of the echo system. The following software was employed in the design: Embedded C, MySQL Connector/ODBC, C\#. Net, PHP My SQL, WampServer, Gliffy online developer and Easy EDA

The echo system is broken down into 5 simple levels as shown in figure 1:

$\checkmark$ Greenhouse farm

$\checkmark$ Embedded systems

$\checkmark$ Supply chain system

$\checkmark$ Database

$\checkmark$ The connecting web

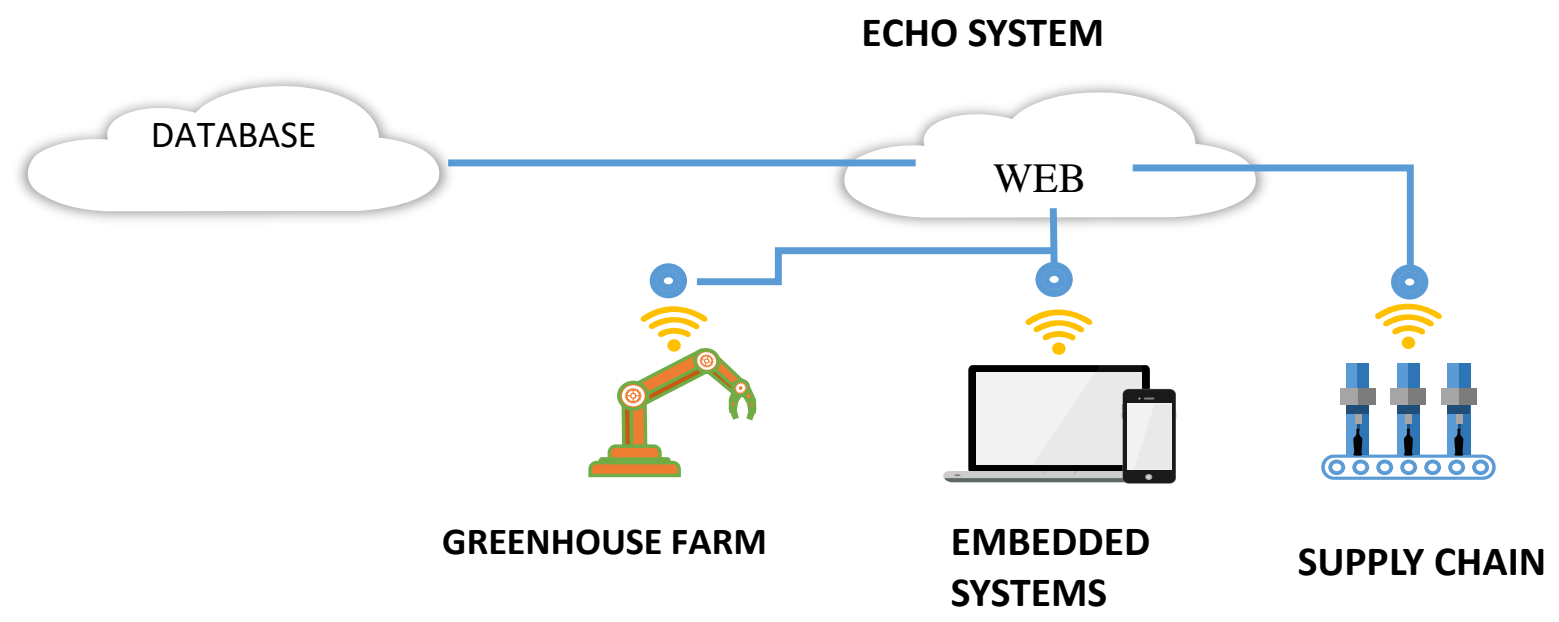

Fig. 1 The Proposed Echo System

\section{i. $\quad$ Greenhouse Farm Architecture}

The greenhouse was constructed using a rubber glass material with embedded devices attached to the outer corner of the greenhouse, while a mushroom plant is placed inside the box as an exemplary plant,

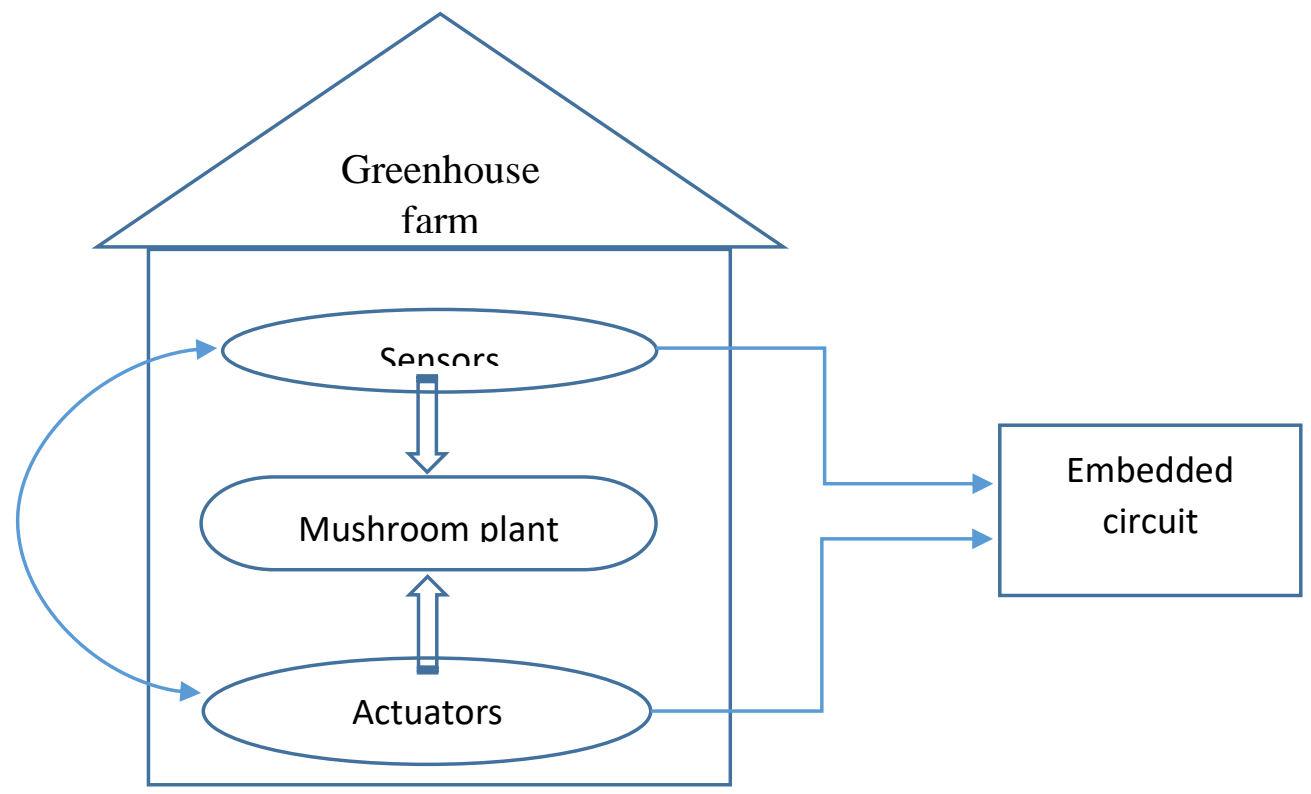

Fig. 2 The Proposed Greenhouse Smart Farm 
The embedded system is made up of multiple components connected together in a circuit box and a corresponding software system to drive it. This will not be possible without knowing what mushrooms need, in a more industrial scenario one would have to consider the environmental requirements of the crop being produced and also consider compatibility if multiple crops will be grown simultaneously to meet consumer demand, these details are important to generate enough data for precision farming, which is the end product of smart farming.

\section{Circuit Description}

The embedded circuit consists of a sensor subsystem which is a set of tools for environmental data collection and all the sensors are connected to a microcontroller board called the Arduino board. Sensors are used to regulate or provide conducive growth conditions for mushroom cultivation. Parameters like light and moisture were sensed and values are then maintained as control variables. The control subsystem Actuators are a set of devices used to control the airflow (fan) and water availability (pump). See figure 2.

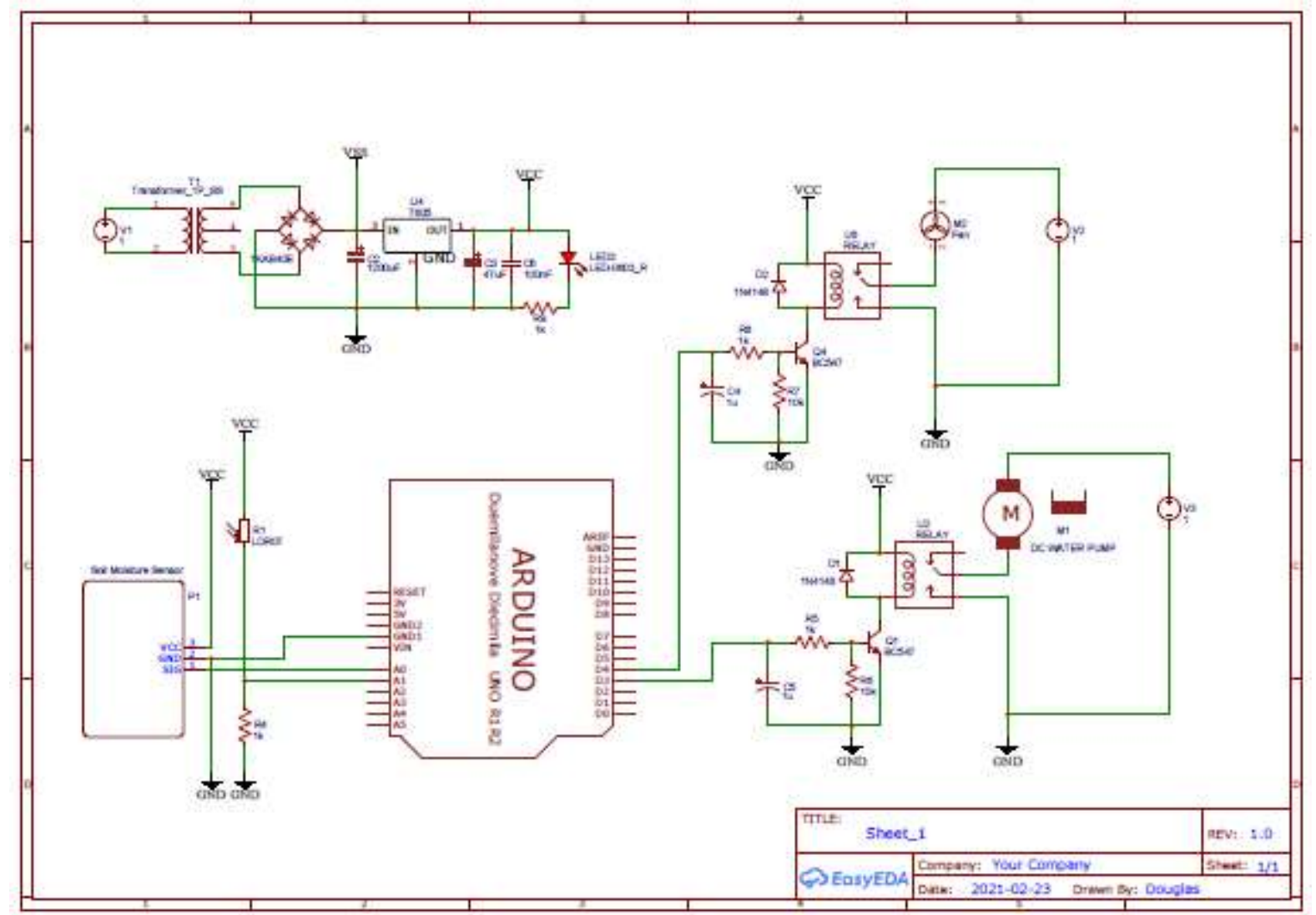

Fig. 3 Circuit diagram of the Propose System

The microcontroller (U1) receives analogue values directly proportional to the quantity under consideration. These quantities include light intensity and soil moisture respectively. These analogue values are then processed and compared with a reference value after which a precise decision is taken hence regulating the respective quantity.

Sensors used include Light Dependent Resistors (LDR) and the soil moisture sensor which are used to read the light intensity from the sun or other artificial light source and the amount of water present in the mushroom substrate.

The system can be powered by a 240VAC from the grid or backup power supply and does not consume too much energy as all the operations are automated so it does not run all the loads at all times. The signal unit requires DC power to run the microcontroller and other DC components so a transformer power supply is designed to adequately power the system.

\section{ii. Control Interface}


Information collected from the environment is digital and cannot be visualized by the user so a visual output is highly recommended. In this design, an Arduino software serial monitor is utilized to visualize and control the activities of the sensor and it also provides a link to the dashboard (back end) of the supply chain web application.

\section{iii. $\quad$ Supply Chain System}

This system is concerned with distributing products via a web interface, providing a link from the greenhouse farm directly to consumers. An Electronic commerce technology (ECT) is the web technology used to provide a consumer-friendly business environment for the echo system. It is divided into a front end to sell products to consumers and a back end to monitor activities and manage requests. The functions of the supply chain system back end are to aid farm owners to carry out customer relationship management (back end), visualize greenhouse activity reports, visualize sales analysis chart, upload products to market and manage order requests. The functions of the supply chain system front end are to enable consumers to shop for products, make payment from their bitcoin addresses and give feedback interactions about services

\section{iv. Database}

The database holds all information of activities being carried out on the perception and application layers through the network layer with a connection called "Mysql Connector" This provides a communication link between all events on the system and the database. A wamp server was used to host the database of this system, it provides easy database management features and a good table structure.

\section{Results And Discussion}

This section is concerned with the testing of the Smart farming echo system. The testing was done according to the functional specifications

\section{i. Control Interface}

This is like a remote control for smart farm owners to manipulate sensors from the comfort of a host device. The Control interface is tested by establishing a link to the greenhouse system via the COM 11 port of a host $\mathrm{PC}$ as shown in figure 4.1

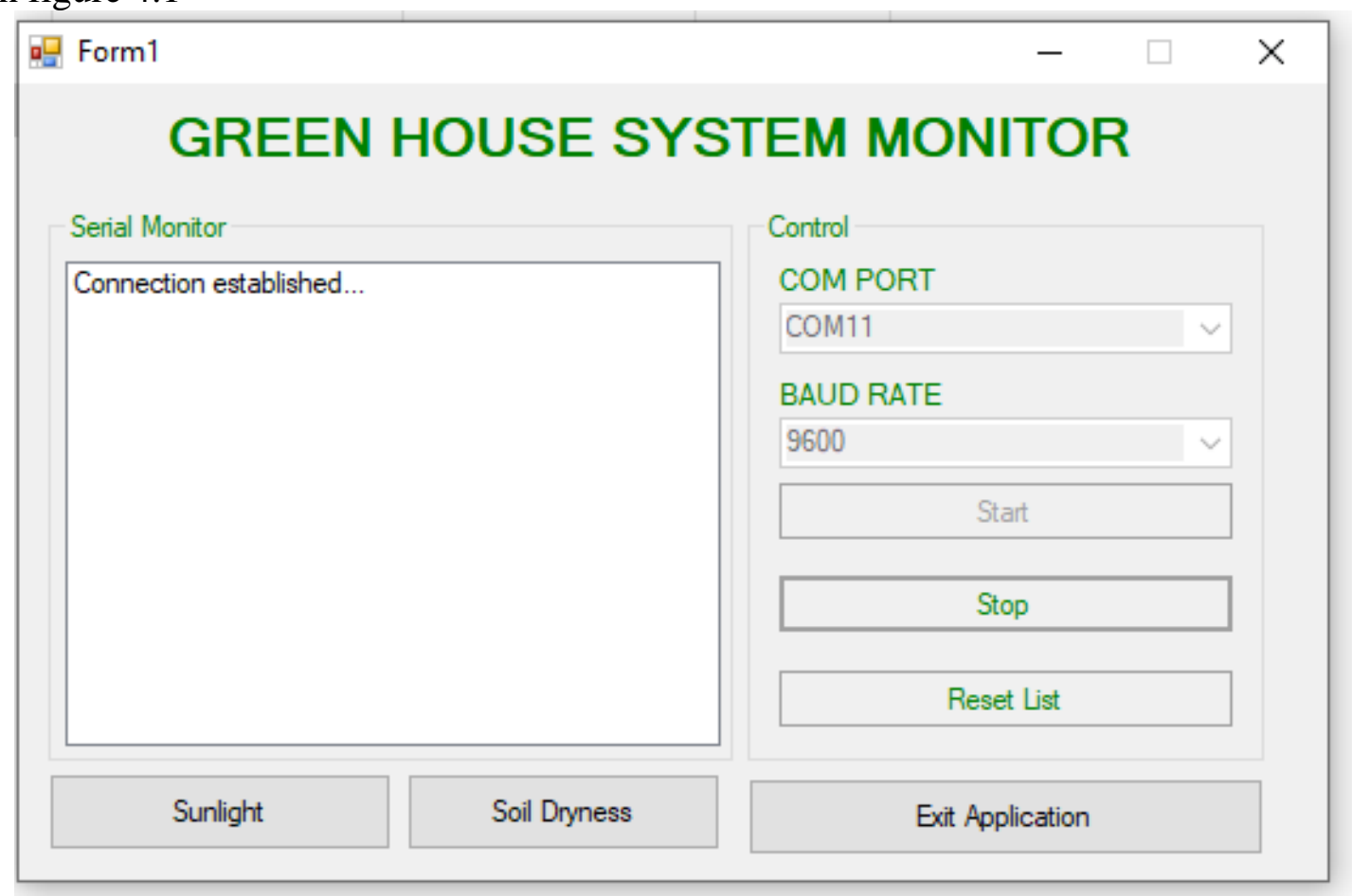

Fig. 4 Communication link between Hardware and control interface

The light-dependent resistor functionality is tested by clicking the sunlight button on the interface, the result would be to pump water if light levels are high, or do nothing if normal. 


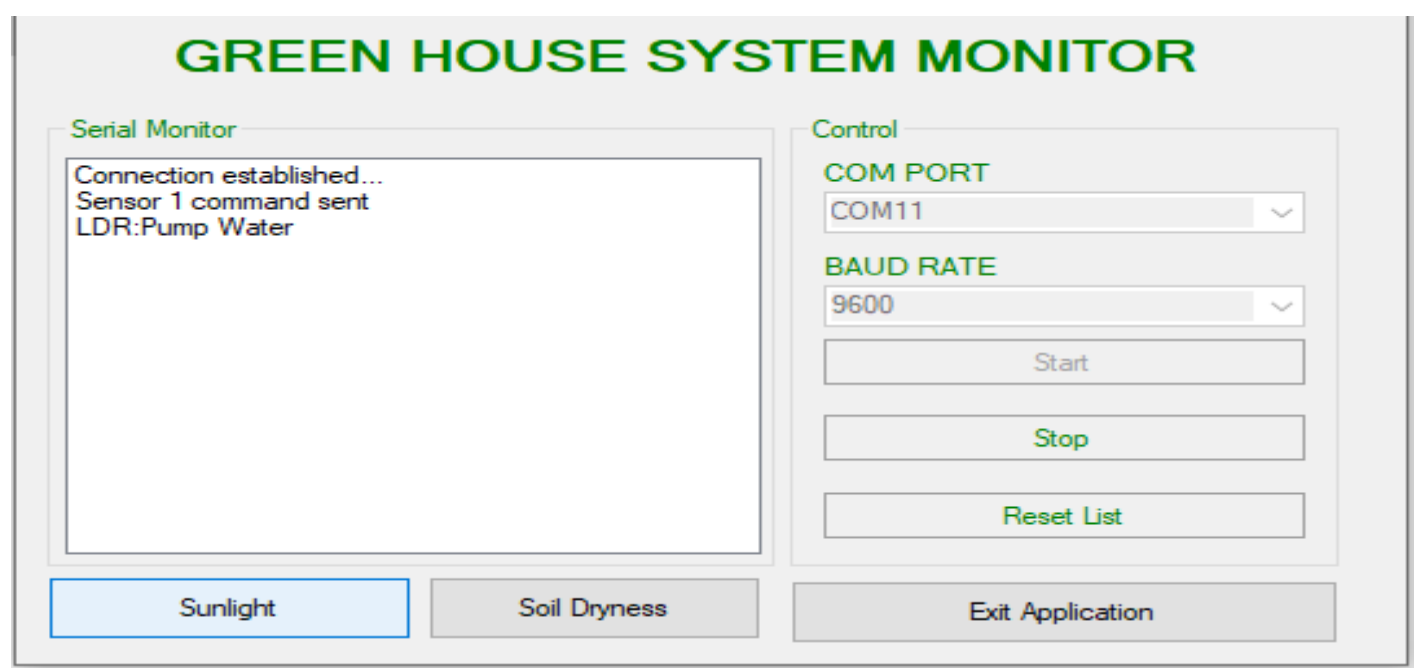

Figure 5. LDR test result

The soil moisture sensor is tested by clicking on the soil dryness button on the interface, the result shows that soil levels are low and the pump is activated.

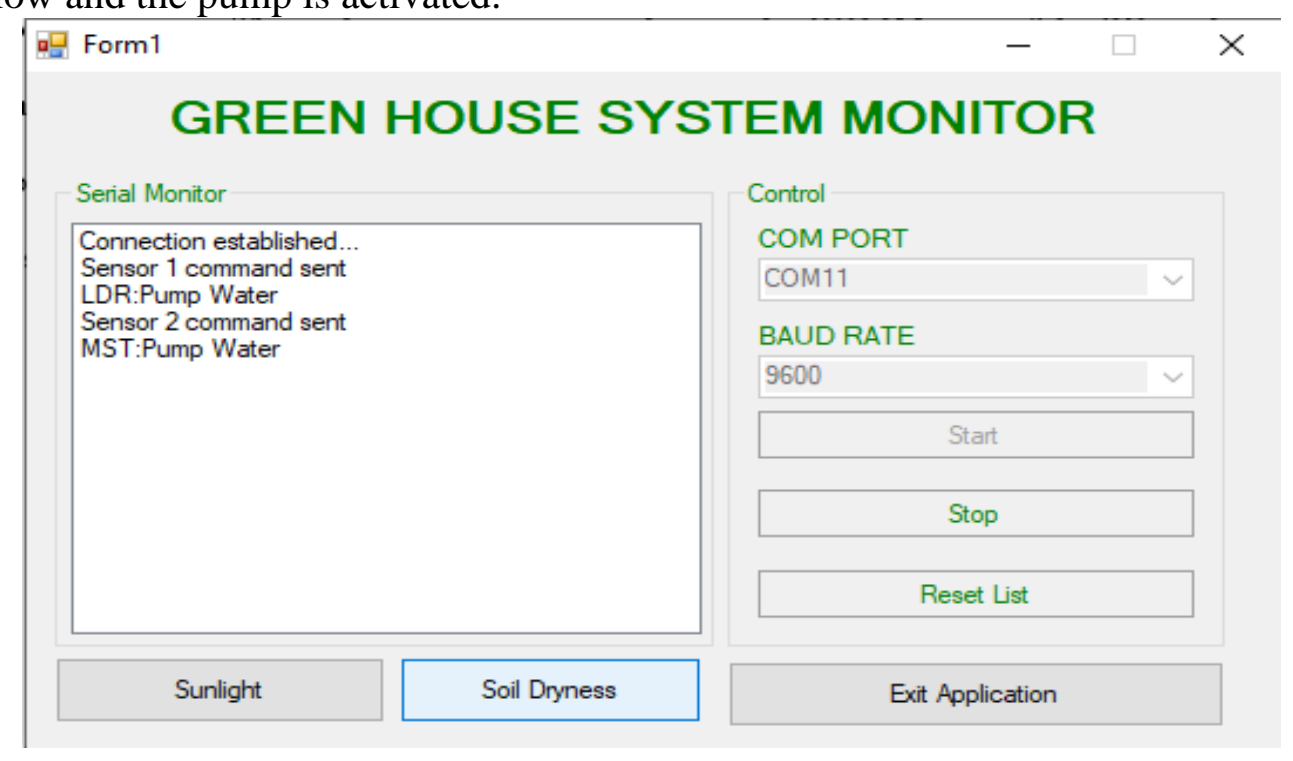

Fig. 6 Soil moisture sensor test result

\section{ii. $\quad$ Back End Testing and Results}

The back end is only accessible to smart farm owners as part of the supply chain management features. The Feedback from customers in any business is fundamental for good customer relationship management (CRM), the feedback functionality was successfully tested such that customer feedback replies on the front end can be viewed and attended to on the back end. 


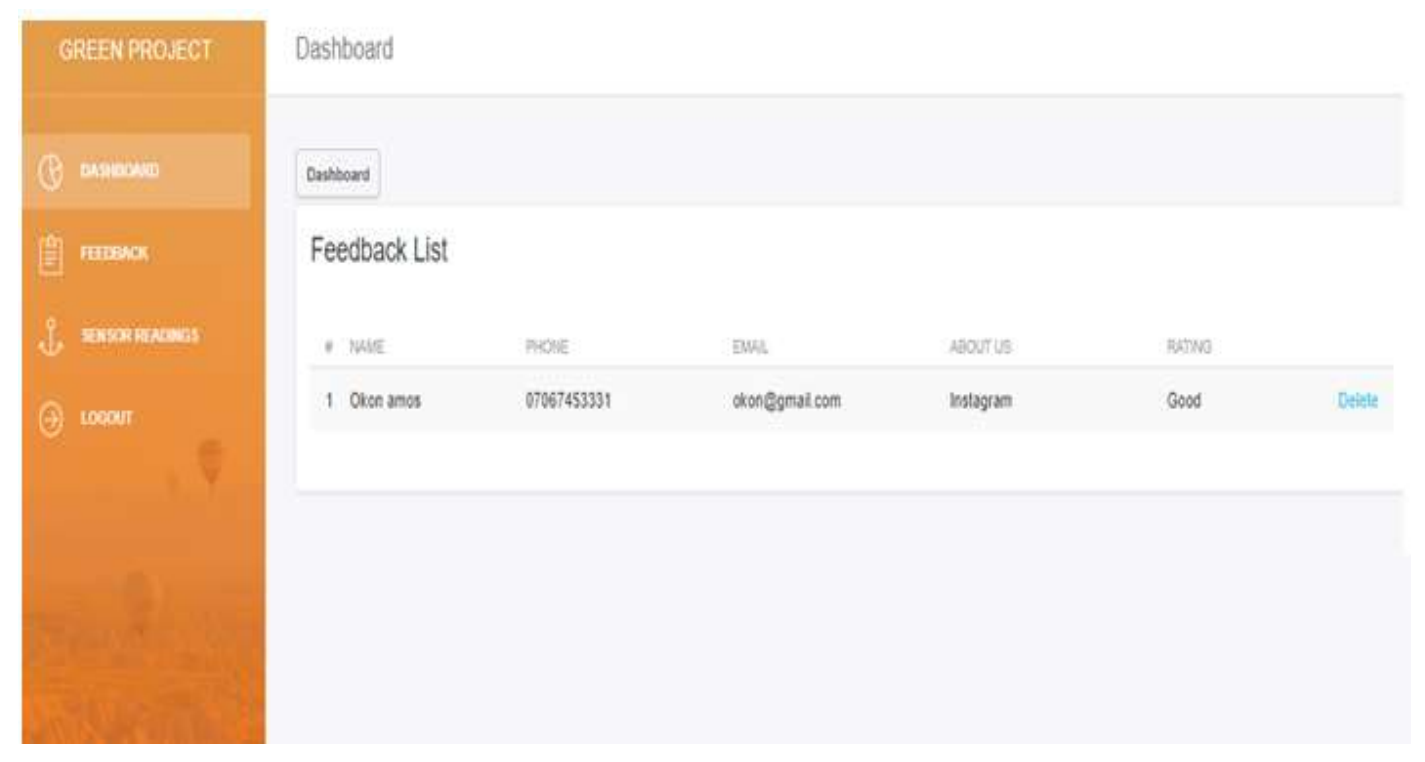

Fig. 7 CRM test result

Sensor Activities from the control interface is communicated to ECT and can be monitored from the back end, showing the number of times environmental conditions are being checked.

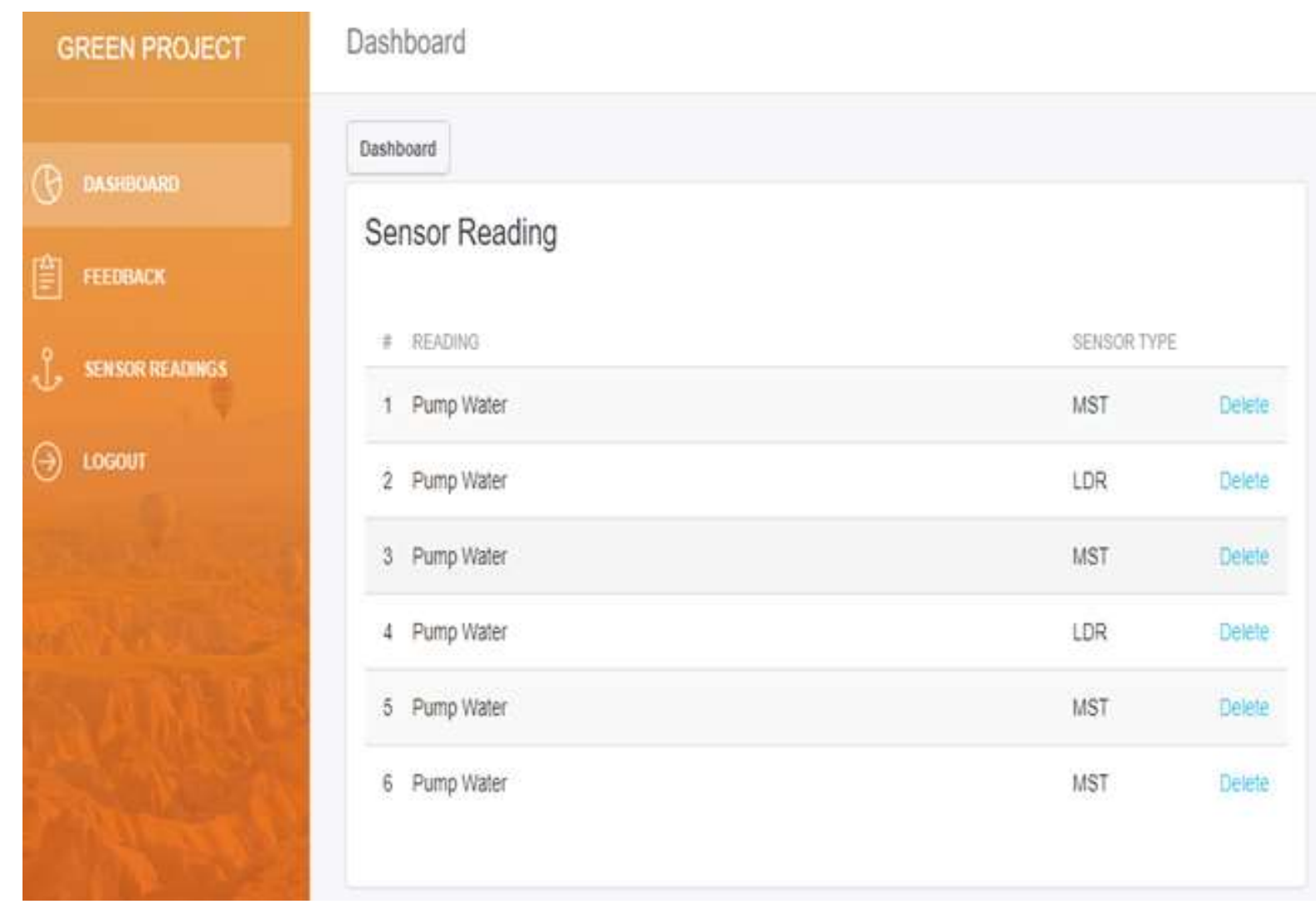

Fig. 8 Greenhouse monitoring result

The back-end also provides smart farm owners with insights on their business, the graph in figure 9 shows a price to quantity curve allowing backend users to keep track of their sales and income. 


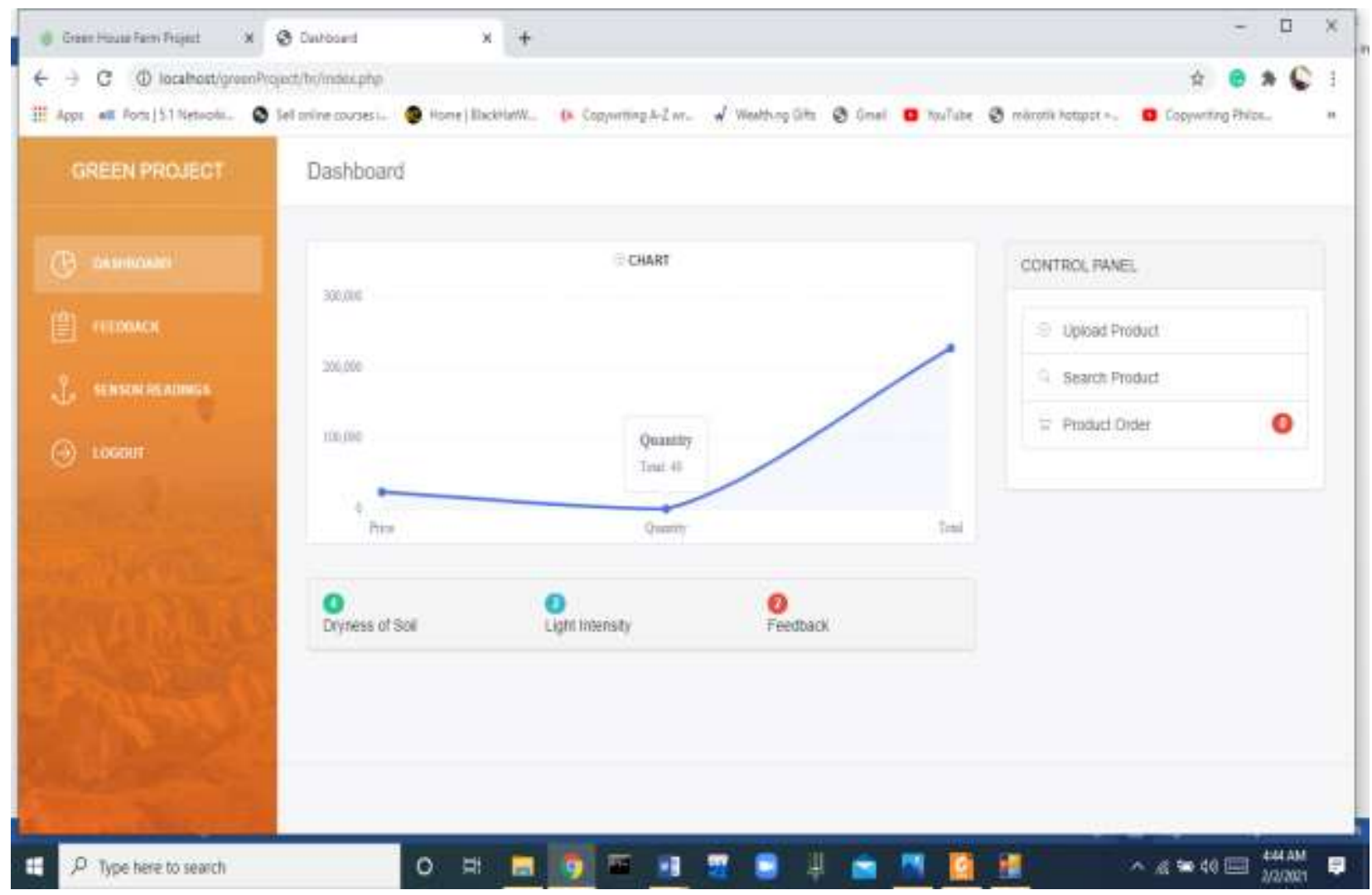

Fig.9 Business analysis test result

Also, the Back-end users can upload products directly to the market with images and NAFDAC license numbers of the products for customer satisfaction. The back-end user receives notifications of orders placed by customers on the front end. Orders that have been attended to are highlighted green while pending orders are marked red.

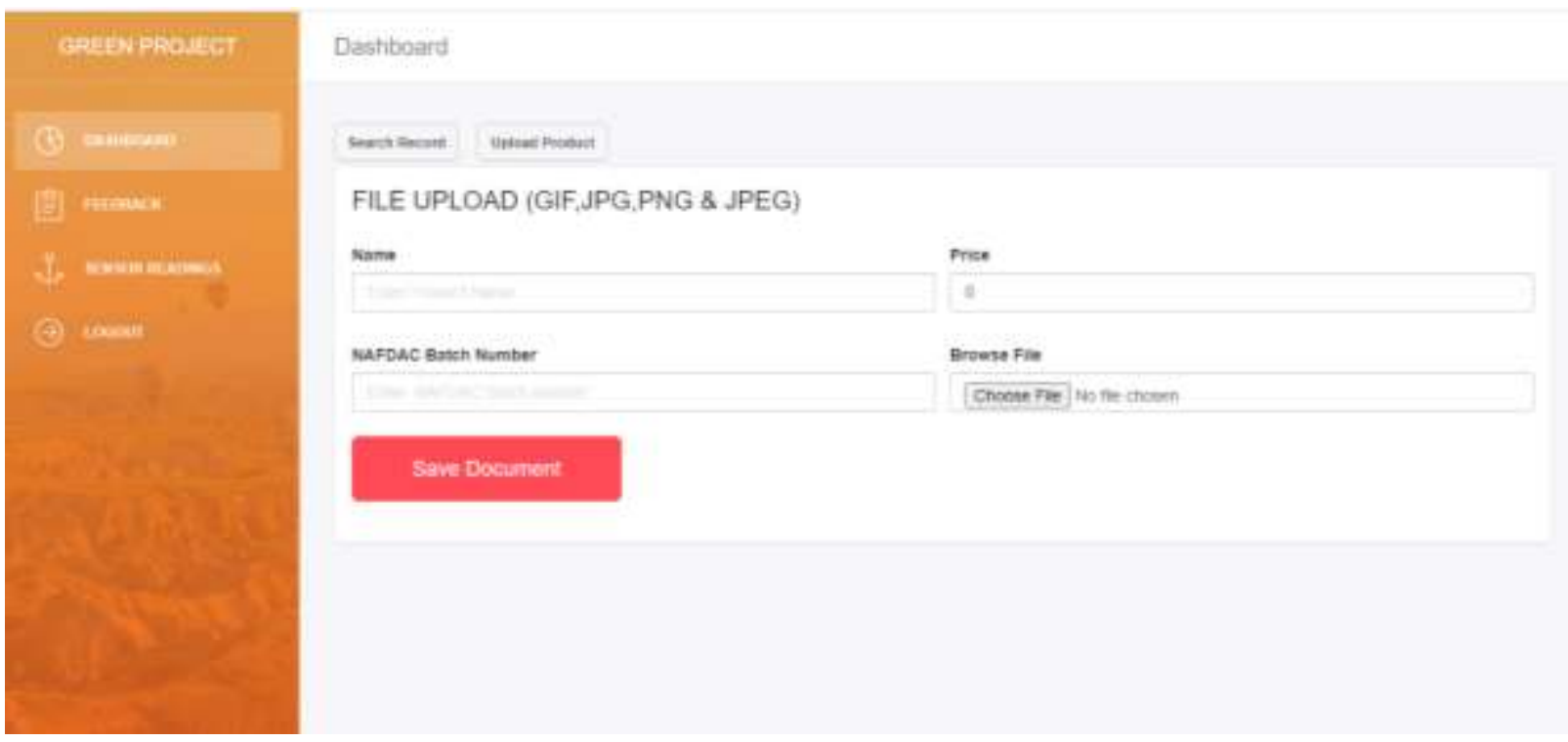

Figure 10 Product Upload test

Another things done at the back end is to receive notifications of orders placed by customers on the front end. Orders that have been attended to are highlighted green while pending orders are marked red. 

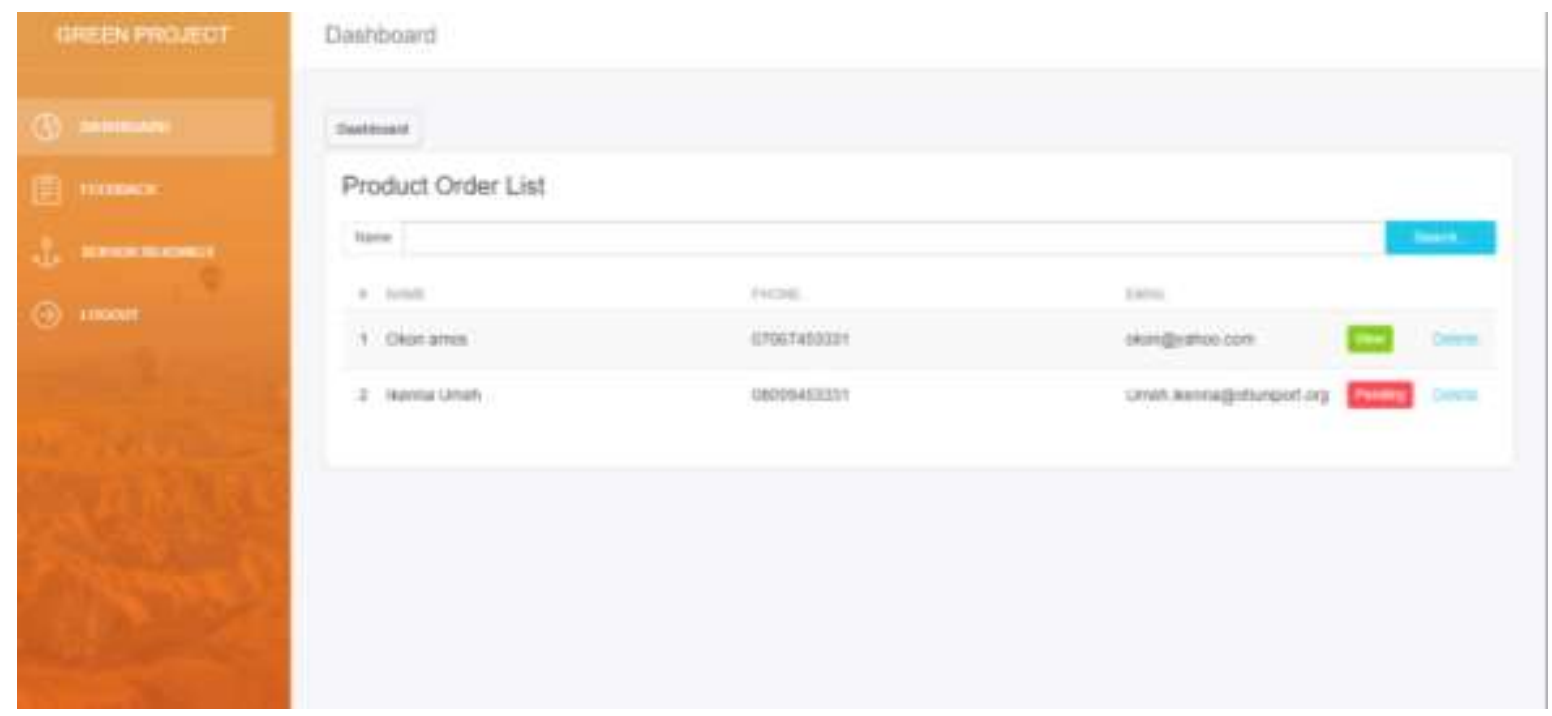

Fig11 Product order list showing one pending order

\section{iii. $\quad$ Front End Testing}

This is the part of the ECT that interacts with potential buyers/ customers who want to purchase farm products that have been uploaded from the back end. customers will be able to buy any desired quantity and carry out many other functions such as: Shopping Cart Management, Product Ordering, License Information, Payment and Feedback from customers who share observations to provide smart farm owners to improve the quality of their service.

\section{Conclusions}

In conclusion, the work focused on developing a greenhouse smart farm echo system capable of cultivating mushrooms and deploying them directly to a market environment, this enables smart farmers to maintain a healthy farm to business link and a sustainable supply chain. The design presented in this work is easy to understand and can be used by farmers who want to automate their farming processes and gain more inclusion in the commodity markets. The result shows that the designed system is functional.

\section{Reference}

1. Atzori, L.; Lera, A.; Morabito, G.(2014). From "smart objects" to "social objects": The next evolutionary step of the internet of things. IEEE Commun. Mag. 2014, 52, 97-105.

2. Babar S, Stango A, Prasad N, Sen J, Prasad R. (2011) Proposed embedded security framework for Internet of Things (IoT). IEEE International Conference on Wireless Communication, Vehicular Technology, Information Theory and Aerospace \& Electronic Systems Technology.

3. Badia-Melis R, Garcia-Hierro J, Ruiz-Garcia L, Jimenez-Ariza T, Robla Villalba J I, Barreiro P. (2014). Assessing the dynamic behavior of WSN motes and RFID semi-passive tags for temperature monitoring. Computers and Electronics in Agriculture, 103: 11-16.

4. Ruiz-Garcia L, Steinberger G, Rothmund M. (2010). A model and prototype implementation for tracking and tracing agricultural batch products along the food chain. Food Control, 21(2): 112-121.

5. Banhazi T, Lehr H, Black J, Crabtree H, Schofield P, Tscharke M, Berckmans D. (2012). Precision livestock farming: An international review of scientific and commercial aspects. International Journal Agriculture \& Biological Engineering. (3):1-10.

6. Berckmans D. (2014). Precision livestock farming technologies for welfare management in intensive livestock systems. Rev. Sci. Tech. off. Int. Epiz. 33(1):189-196.

7. Projections of population growth - Wikipedia https://en.wikipedia.org > wiki $>$ Projections_of population 